\title{
EMISSION CHARACTERISTICS OF BIODIESEL DERIVED FROM USED COOKING OIL BLENDED WITH DIESEL IN THE PRESENCE OF POTASSIUM HYDROXIDE (KOH) CATALYST AS ALTERNATIVE FUEL FOR DIESEL ENGINES
}

\author{
M. Saravanakumar ${ }^{1, *}$, M. Prabhahar ${ }^{1}$, Sangeetha Krishnamoorthi1 \\ and S. Sendilvelan ${ }^{2}$ \\ ${ }^{1}$ Department of Mechanical Engineering, Aarupadai Veedu Institute of Technology, \\ Chennai- 602 105, India. \\ ${ }^{2}$ Department of Mechanical Engineering, Dr. M.G.R Educational and Research Institute, \\ Chennai-600 095, India \\ *E-mail: mprabhahar@gmail.com
}

\begin{abstract}
The fossil fuels usage in the world has been increasing continuously due to the energy demand, which leads to a decline in fossil fuel reserve. The increase in the cost of fossil fuels and the environmental pollution lead a search for an alternative energy. The energy should be renewable, harmless and non-polluting. Used cooking oil methyl ester is derived through transesterification process by using Used Cooking Oil (UCO) and methanol in the presence of Potassium hydroxide $(\mathrm{KOH})$ catalyst. Emission characteristics have been investigated the used cooking oil and their blends with diesel.B20K and B100K reduced the carbon monoxide (CO) by $4.5 \%$ and $32.27 \%$, hydrocarbon (HC) emission by $28.26 \%$ and $45.65 \%$, particulate matter by $3 \%$ and $19.13 \%$ and smoke emission by $7.25 \%$ and $28.27 \%$, respectively compared to diesel at full load. On the other hand, $\mathrm{B} 20 \mathrm{~K}$ and $\mathrm{B} 100 \mathrm{~K}$ increased the $\mathrm{NO}_{\mathrm{x}}$ emission by $7.3 \%$ and $18 \%$, respectively compared to diesel at the rated output. The emissions of carbon monoxide, hydrocarbon, smoke density and particulate matters were reduced and there was a slight increase in oxides of nitrogen with the used cooking oil methyl ester (UCOME), as a renewable harmless and non-polluting substitute for diesel engines.
\end{abstract}

Keywords: Used Cooking Oil, Biodiesel, Diesel Engine, Emissions, Soot, Oxides of Nitrogen.

○ $\mathrm{RASA}$ ĀYAN. All rights reserved

\section{INTRODUCTION}

Consumption of energy is increasing worldwide in various forms for a variety of purposes. The amount of consumption is directly proportional to a society's growth. Today developing countries are prospering through economic reforms and are becoming technologically advanced. The reason to find out for renewable sources has been the harmful emission reduction and increased consumption day by day and the increasing cost worldwide ${ }^{1}$. Biodiesel can be considered a new technology, considering that all these years' consumers have had to settle for traditional diesel. Biodiesel is not harmful to the environment ${ }^{2}$. A vehicle tends to pollute the environment and emits harmful gasses, whereas if the engine is using biodiesel, it emits no harmful gasses and rather keeps the environment pollution free ${ }^{3}$.

Biodiesel may not require an engine modification. Biodiesel can be blended with diesel to improve the efficiency of the engine without any hassles. Biodiesel is cheap. You can even make biodiesel in your backyard. If your engine can work with biodiesel fuel alone, then you really need not go to the gas station to buy fuel ${ }^{4}$. You can just manufacture some for your own personal use. Any Vehicle using Biodiesel has very low idle starting noise. It is noted that biodiesel has a Cetane number of over $100^{5}$.

Cetane number is used to measure the quality of the fuel's ignition. If the fuel has a high Cetane number, it can be sure that what one gets is a very easy cold starting coupled with a low idle noise. Biodiesel is cost-effective because it is produced locally ${ }^{6}$. A variety of fuels can be produced from biomass resources 
RASĀYAN J. Chem.

Vol. 11 | No. 1 |372 - 377 | January - March | 2018

including liquid fuels, such as bioethanol, methanol, biodiesel, and gaseous fuels, such as hydrogen and methane? .

The term waste cooking oil (WCO) refers to vegetable oil which has been used in food production and which is no longer viable for its intended use. WCO arises from many different sources, including domestic, commercial and industrial ${ }^{8}$. WCO is a potentially problematic waste stream which requires being properly managed. The disposal of WCO can be problematic when disposed of, incorrectly, down kitchen sinks, where it can quickly cause blockages in sewer pipes when the oil solidifies.

Properties of used frying oil after it gets into sewage system are conducive to corrosion of metal and concrete elements. It also affects installations in waste water treatment plants. Thus, it adds to the cost of treating effluent or pollutes waterways. Any fatty acid source may be used to prepare biodiesel. Thus, any animal or plant lipid should be a ready substrate to produce biodiesel. From this UCO, the bio diesel can be produced through transesterification process 9 .

The properties of the fuels were determined using standard methods. The study was carried out to investigate the performance, combustion and emission characteristics of used cooking oil methyl esters and their blends with diesel in varying proportions. A single cylinder, water cooled, four stroke diesel engine was used for this work. Experiments were conducted when the engine was fueled with used cooking oil methyl ester and their blends with diesel in proportions of 20:80 and 100\% (by volume), which are generally called as $\mathrm{B} 20 \mathrm{~K}$ and $\mathrm{B} 100 \mathrm{~K}$ respectively. The smoke meter was used to measure the smoke density in HSU. The performance of the engine was evaluated in terms of brake specific fuel consumption, brake thermal efficiency. The emission characteristics of the engine were studied in terms exhaust gas temperature, the concentration of NOx, $\mathrm{CO}$, particulate matter and smoke density.

The results obtained for UCOME, and their blends with diesel were compared with the results of diesel. Engine modification not needed if the blends proportion is around 20\% Biodiesel blends with diesel. Asian regions are the potential area since the availability and have to restrict the emissions drastically in near future ${ }^{10}$.

\section{EXPERIMENTAL}

A series of samples prepared alkali catalyzed method to produce biodiesel. Methanol was blended with $\mathrm{KOH}$ ( $1 \mathrm{wt} . \%$ of oil) added to the reactor. The mechanism of acid catalyzed transesterification of vegetable oil (for a monoglyceride) is shown in Fig.-1. However, it can be extended to di- and triglycerides. The protonation of the carbonyl group of the ester leads to the carbocation, which after a nucleophilic attack of the alcohol produces a tetrahedral intermediate. This intermediate eliminates glycerol to form a new ester and to regenerate the catalyst. Generally, the catalyst can be used acid, alkali, and biocatalyst in transesterification method. If more water and free fatty acids are there in triglycerides, the acid catalyst can be used. Table-1 shows the properties of various blends prepared through the transesterification process.

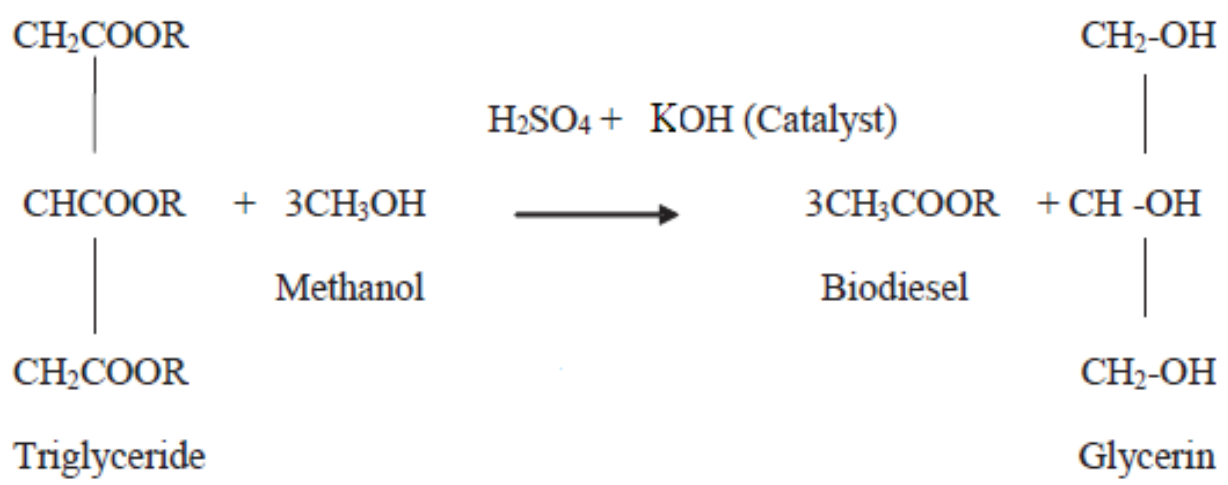

Fig. -1: Transesterification Process ${ }^{11}$

The performance tests were carried on a single cylinder, four strokes, and naturally aspirated and watercooled Kirloskar computerized diesel engine test rig. This computerized test rig was used for reading the test parameters. The experiment covered a range of loads $(0 \%, 25 \%, 50 \%, 75 \%$ and $100 \%)$. 
RASĀYAN $J$. Chem.

Vol. 11 | No. 1 | 372 - 377 | January - March | 2018

Table-1: Properties of Various Blends

\begin{tabular}{c|c|c}
\hline Fuel & Fuel Density $\left(\mathrm{kg} / \mathrm{m}^{3}\right)$ & Calorific Value $(\mathrm{kJ} / \mathrm{kg})$ \\
\hline Diesel & 830 & 42000 \\
\hline B20K & 884 & 41392 \\
\hline B100K & 914 & 37848 \\
\hline
\end{tabular}

\section{Carbon Monoxide Emissions}

\section{RESULTS AND DISCUSSION}

From the Fig.-2, it can be observed that there is significant $\mathrm{CO}$ reduction for tested biofuels at all loading conditions compared with diesel.

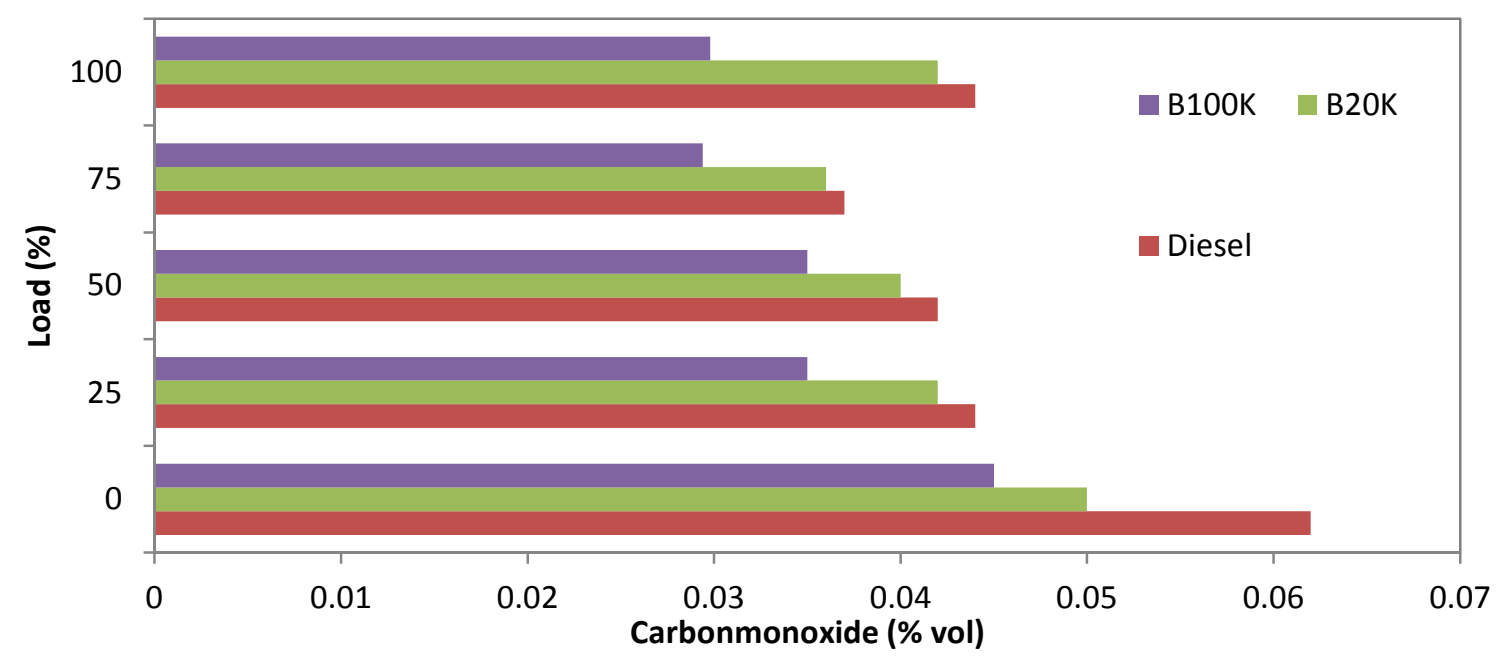

Fig.-2: Carbon monoxide (\% Vol) Vs Load (\%)

Compared with diesel fuel the biodiesel blends shows lower carbon monoxide emission because of low viscosity and good spray characteristic of biodiesel blends. Complete combustion of fuel due to higher availability of oxygen results in lower carbon monoxide ${ }^{12}$. At engine full load, results show lower $\mathrm{CO}$ levels when running $100 \%$ biodiesel relative to the $20 \%$ biodiesel and neat diesel. The lower CO of $0.0298 \%$ vol. was obtained, when the B100K fuel was tested, $0.042 \%$ vol, when B20K has tested and $0.044 \%$ vol, when diesel fuel was tested at full load conditions.

\section{Unburned Hydrocarbon Emissions}

The Unburned hydrocarbons emissions measured for test engine as a function of engine load and biodiesel blending ratio are shown in Fig.-3.

UHC not depends on engine load so the variation is about 5 to $10 \%$ only in the case of unburnt hydrocarbon. Improper mixed is another reason for the UHC emission, for the specific engine, the mixing degree depends mainly on the engine speed ${ }^{13}$. The UHC is increased due to low oxidation rate at low temperature or it may be due to low oxygen contents ${ }^{14}$. The used cooking oil having oxygen atoms in its structure enhance the oxidation of fuel elements and so UHC emissions are reduced. The lower HC of 25 ppm was obtained, when the B100K fuel was tested, 33 ppm when B20K was tested and 46 ppm when diesel was tested at full load conditions.

\section{Oxides of Nitrogen}

The variation of NOx emission with various ratios of used cooking oil biodiesel is shown in Fig.-4. It is observed that the NOx emission is increasing trend than that of diesel. NOx emission is higher by at full load condition ${ }^{15}$. The reason for higher NOx emission could be due to higher peak flame temperature ${ }^{16}$. 
RASĀYAN J. Chem.

Vol. 11 | No. 1 | 372 - 377 | January - March | 2018

The lower NOx of 1200 ppm was obtained, when the diesel fuel was tested, 1352 ppm when B20K was tested and $1541 \mathrm{ppm}$ when B100K was tested at full load conditions ${ }^{17}$.

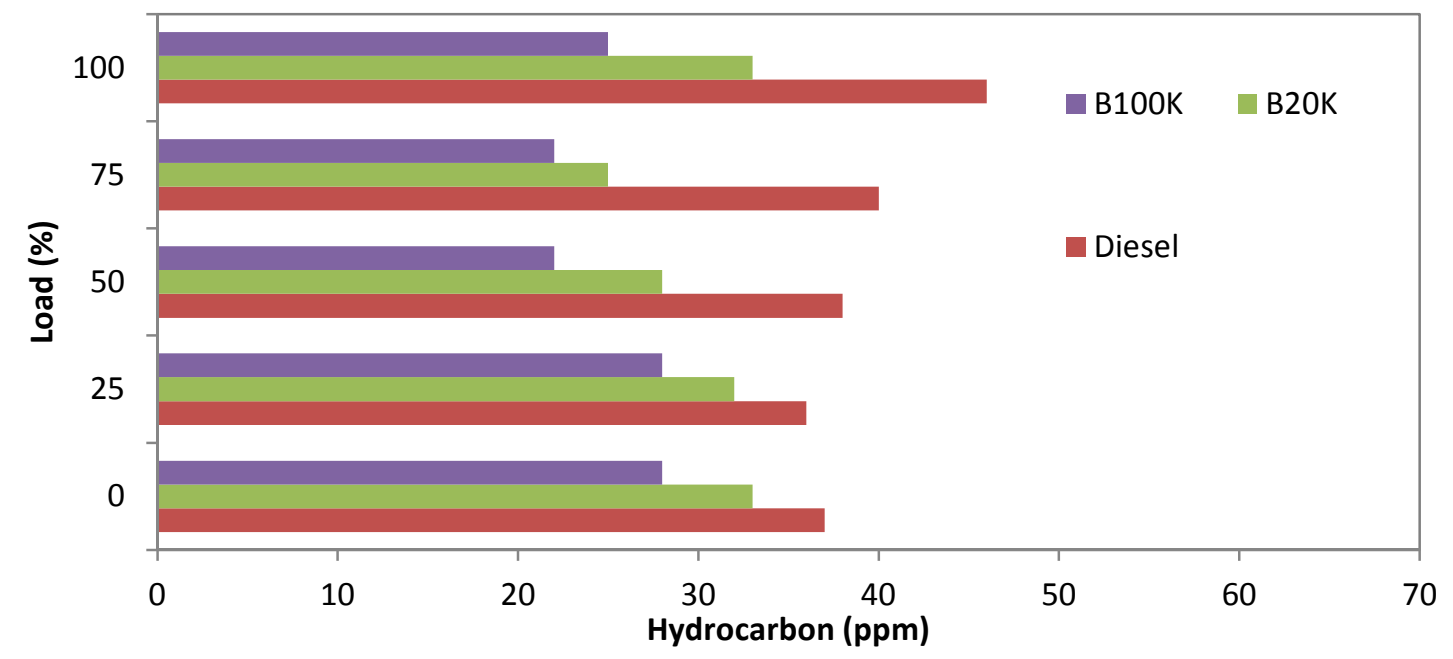

Fig.-3: Hydrocarbon (ppm) Vs Load (\%)

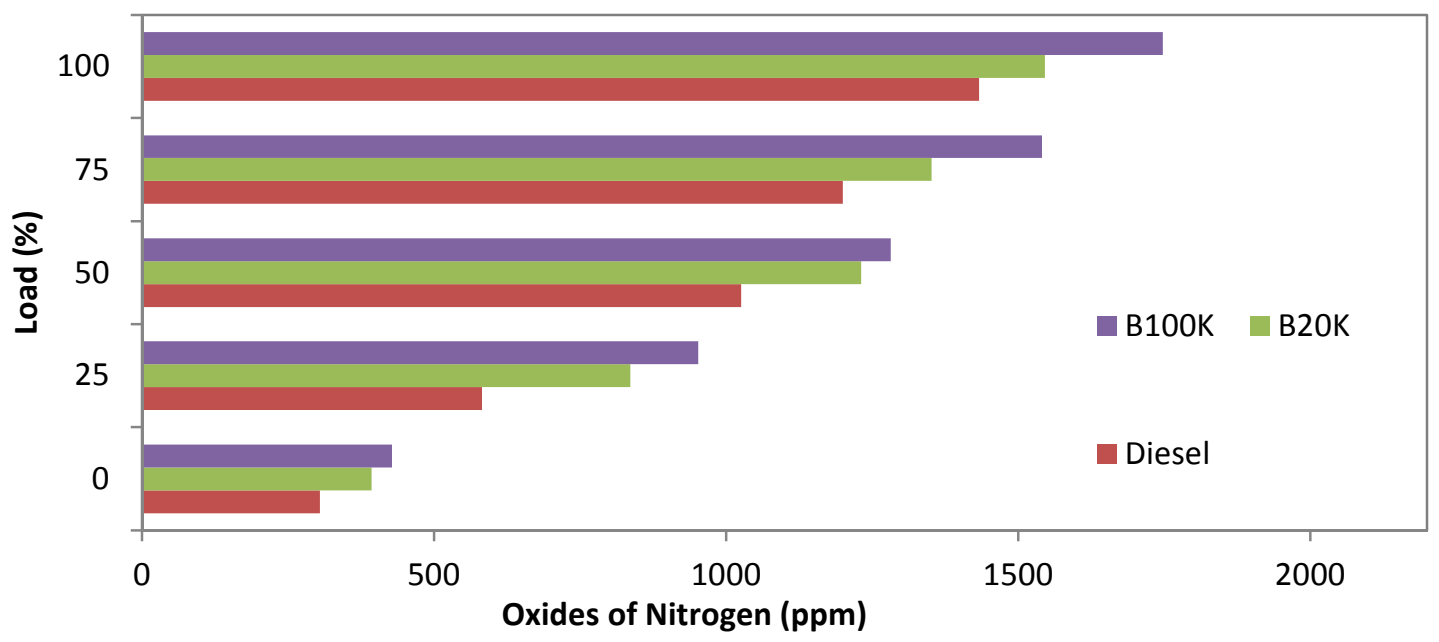

\section{Smoke Density}

Fig. -4: Oxides of Nitrogen (ppm) Vs Load (\%)

Particulate matter emissions are due to the incomplete combustion in the burning process. Due to the availability of oxygen in the biodiesel complete combustion takes place in the cylinder. Particulate matters are higher for diesel than the other fuels used for the testing. When the blends are increased the particulate matter is reduced ${ }^{18}$. The lowest particulate emission of $0.51 \mathrm{~g} / \mathrm{min}$ was obtained from B100K fuel as shown in Fig.-5.

Smoke density is higher in diesel than all other biodiesel blends. The smoke density of BK blends are compared with diesel are shown in Fig.-6. When the blends are increased in percentage, the smoke density is reduced. The lower smoke density of 18.8 HSU was obtained, when the fuel B100K was tested at full load conditions. Since BK and its blends are oxygenated fuels, they endorse better combustion and the outcome is in the reduction of smoke density ${ }^{19,20}$.

\section{CONCLUSION}

The biodiesel can be produced from used cooking oil to reduce environmental pollution. The emission characteristics of this biodiesel derived through transesterification process by using used cooking oil 
RASĀYAN J. Chem.

Vol. 11 | No. 1 | 372 - 377 | January - March | 2018

(UCO) and methanol in the presence of Potassium hydroxide $(\mathrm{KOH})$ catalyst shows favorable emission reduction as reported below:

1. The carbon monoxide emission was reduced by $4.5 \%$ with $\mathrm{B} 20 \mathrm{~K}$ biodiesel and $32.27 \%$ with B100K fuel.

2. The hydrocarbon emission was reduced by $28.26 \%$ with $\mathrm{B} 20 \mathrm{~K}$ biodiesel and $45.65 \%$ with B100K fuel.

3. The Oxides of nitrogen emission was increased by $7.3 \%$ with $\mathrm{B} 20 \mathrm{~K}$ biodiesel and $18 \%$ with B100K fuel.

4. The particulate matter was reduced by $3 \%$ with B20K biodiesel and $19.13 \%$ with B100K fuel.

5. The smoke density was reduced by $7.2 \%$ with B20K biodiesel and $28.27 \%$ with B100K fuel.

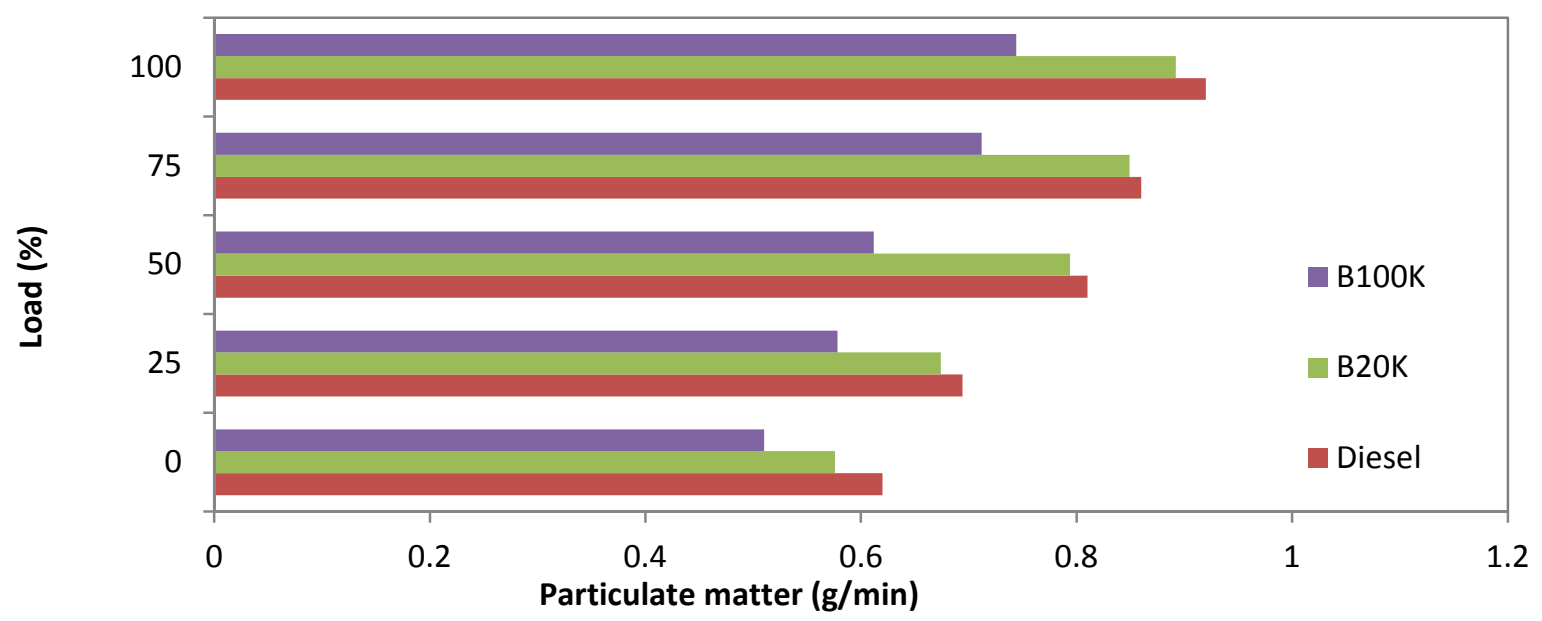

Fig.-5: Particulate matter (g/min) Vs Load (\%)

It is concluded that used cooking oil methyl esters and their blends can be directly used in a diesel engine without any engine modifications. Compared to all fuels, the B20 blends gives all the results almost closer to diesel, the B20K is better because B20K has better calorific value and density, which are closer to diesel.

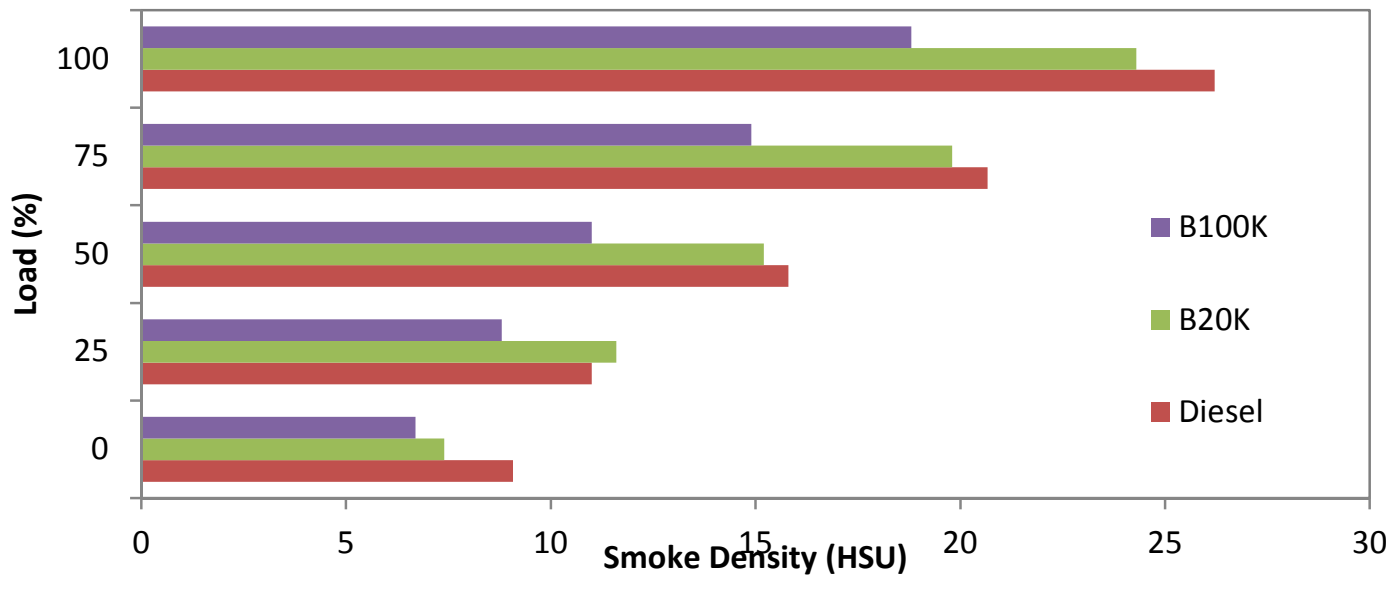

Fig.-6: Smoke Density (HSU) Vs Load (\%)

ACKNOWLEDGEMENT

The authors would like to thank the Dr. M.G.R. Educational and Research Institute, Aarupadai Veedu Institute of Technology, for support through the Research facilities at the University Research labs. 
RASĀYAN J. Chem.

Vol. 11 | No. 1 |372 - 377 | January - March | 2018

\section{REFERENCES}

1. L. Sassykova, A. Nalibayeva and Y. Aubakirov, Orient. J. Chem.,33 (4), 1941(2017).

2. Z. Yaakob, M. Mohammad, M. Alherbawi, Z. Alam and K. Sopian, Renewable and Sustainable Energy Reviews, 184(2013).

3. W.A. Kawentar, A. Budiman, In Energy Procedia,32, 190(2013).

4. S. Sendilvelan andK. Bhaskar, Orient. J. Chem.,33 (4),2111(2017).

5. S. Sendilvelan and K. Bhaskar,World J. Eng., 14 (4), 348(2017).

6. S. Tursynbek, K. Toshtay, I.O. Pustovalov and F.Y. Abdrakova, Rasayan J. Chem., 10 (4), 1145(2017).

7. D.A. Baiseitov, M.I. Tulepov, L.R. Sassykova, K.K. Kudaibergenov andZ.A. Mansurov, Int. J. Chem. Sci., 13 (2), 1027(2015).

8. G.G. Muciño, R. Romero, A. Ramírez, S.L. Martínez, R. Baeza-Jiménez and R. Natividad, In Fuel,138, 143(2014).

9. P. Nakpong and S. Wootthikanokkhan, Asian J. Energy Environ.,10 (2), 221(2009).

10. V. Kumar, M. Muthuraj, B. Palabhanvi, A.K. Ghoshal and D. Das, D. Renew. Energy, 68, 560(2014).

11. S. Sendilvelan and K.Bhaskar, K. Rasayan J. Chem.,10(1), 111(2017).

12. E. Navarro López, A. Robles Medina, L. Esteban Cerdán, P.A. González Moreno, M.D. Macías Sánchez and E. Molina Grima, Biomass and Bioenergy, 93, 6(2016).

13. M.G. Kulkarni and A.K. Dalai, Ind. Eng. Chem. Res.,45, 2901(2006).

14. S. Sendilvelan and K. Rajan, Rasayan J. Chem.,10(1), 190(2017).

15. K. Muralidharan and D. Vasudevan, Appl. Energy, 88 (11), 3959(2011).

16. R. Murali Manohar, M. Prabhahar, M and S. Sendilvelan, Eur. J. Sci. Res., 76 (3), 327(2012).

17. M. Prabhahar, S. Sendilvelan, S. Prakash andM. Saravanakumar, Rasayan J. Chem.,10 (4), 107(2017).

18. Y.S. Lin and H.P Lin, Renew. Energy, 35 (9), 1900(2010).

19. L.F. Chuah, S. Yusup, A.R. Abd Aziz, A. Bokhari and M.Z. Abdullah, J. Clean. Prod.,112, 4505(2016).

20. R. Abd Rabu, I. Janajreh and D. Honnery, Energy Convers. Manag.,65, 764(2013).

[RJC-2024/2017] 